\title{
Cortical-basal ganglionic degeneration
}

\author{
D.E. Riley, MD; A.E. Lang, MD; A. Lewis, MB; L. Resch, MD; P. Ashby, MD; \\ O. Hornykiewicz, MD; and S. Black, MD
}

Article abstract-We report our experience with 15 patients believed to have cortical-basal ganglionic degeneration. The clinical picture is distinctive, comprising features referable to both cortical and basal ganglionic dysfunction. Characteristic manifestations include cortical sensory loss, focal reflex myoclonus, "alien limb" phenomena, apraxia, rigidity and akinesia, a postural-action tremor, limb dystonia, hyperreflexia, and postural instability. The asymmetry of symptoms and signs is often striking. Brain imaging may demonstrate greater abnormalities contralateral to the more affected side. Postmortem studies in 2 patients revealed the characteristic pathologic features of swollen, poorly staining (achromatic) neurons and degeneration of cerebral cortex and substantia nigra. Biochemical analysis of 1 brain showed a severe, diffuse loss of dopamine in the striatum. This condition is more frequent than previously believed, and the diagnosis can be predicted during life on the basis of clinical findings. However, as with other "degenerative" diseases of the nervous system, a definitive diagnosis of cortical-basal ganglionic degeneration requires confirmation by autopsy.

NEUROLOGY 1990;40:1203-1212

In every large neurologic practice there are a number of patients whose clinical presentations resemble Parkinson's disease (PD) but with features which clearly distinguish them from classic PD. The characteristics shared with PD are usually the akinesia and rigidity, and the gradual, inexorable progression of the illness. These patients are often lumped into convenient but ultimately meaningless diagnostic groups such as "atypical parkinsonism," "parkinsonism-plus," "akinetic-rigid syndromes," and "multisystem atrophies." Over the past few decades, reports of diligent clinical observations followed by careful pathologic examinations have permitted the recognition and diagnosis of PD-like conditions such as progressive supranuclear palsy ${ }^{1}$ and Shy-Drager syndrome ${ }^{2}$ in living patients with reasonable confidence.

In 1968, Rebeiz et $\mathrm{al}^{3}$ described the clinical and pathologic findings in 3 patients with what they called "corticodentatonigral degeneration with neuronal achromasia." This report identified another distinct group of patients with a superficial similarity to PD. In the interval since its publication, there have been only 10 other patients described, ${ }^{4-6} 6$ in abstract form, and limited reference to a small number of additional patients. ${ }^{7-11}$ We believe that this condition is more prevalent than the scant available literature suggests and that most affected patients are readily recognizable on a clinical basis. We have collected 15 patients diagnosed as having what is now called cortical-basal ganglionic degeneration (CBGD); 2 have died (both diagnosed in life) and showed the typical pathologic features. ${ }^{3} \mathrm{We}$ present the clinical, investigational, and pathologic findings in our patients to date.

Case reports. The following case histories illustrate examples of the clinical evolution of CBGD. The clinical profiles of all patients are given in table 1.

Patient 1. A 52-year-old housewife noted a tremor of her left hand aggravated by action or anxiety beginning in 1976 . Four years later she developed stiffness and slowness of the left arm and leg and slurring of her speech. She began having difficulty arising from a chair, and her left hand became progressively more difficult to use, especially for dressing. Examination disclosed an action tremor of both upper limbs, more prominent on the left, left-sided rigidity and akinesia, and generalized hyperreflexia, also greater on the left. She was given trials of levodopa/carbidopa, propranolol, methysergide, and amantadine without effect. Procyclidine produced only a dry mouth and orolingual dyskinesias; and bromocriptine was abandoned due to dyskinesias and intermittent confusion. Hypertension was noted and treated with methyldopa.

In 1982, her right hand began shaking and became awkward at handwriting. Examination then showed apraxias for both eyelid opening (levator inhibition) and closure as well as apraxias for orolingual and upper limb actions, the left arm being more affected. There was severe reflex blepharospasm. Ocular movements showed impaired pursuit and saccades in all directions, in part due to easy distractibility and spasms of fixation (inability to break gaze). When requested to look in a specific direction, she often stared ahead and stated, "I can't." At other times, she spontaneously managed a full range of ocular motion. Optokinetic nystagmus was normal. There were prominent tongue dyskinesias. Her motor examination now showed pronounced rigidity in the left arm, athetosis in

From Mt. Sinai Medical Center and Department of Neurology (Dr. Riley), Case Western Reserve University, Cleveland, OH; Toronto Western Hospital (Drs. Riley, Lang, Resch, and Ashby), Sunnybrook Medical Center (Drs. Lewis and Black), and Clarke Institute of Psychiatry (Dr. Hornykiewicz), Toronto, ON, Canada; and the University of Vienna (Dr. Hornykiewicz), Vienna, Austria.

Dr. Riley was supported in part by the United Parkinson Foundation.

Received September 13, 1989. Accepted for publication in final form January 19, 1990.

Address correspondence and reprint requests to Dr. David Riley, Movement Disorders Center, Mt. Sinai Medical Center, 1 Mt. Sinai Drive, Cleveland, OH 44106. 


\begin{tabular}{|c|c|c|c|c|c|c|c|c|c|c|c|c|c|c|c|}
\hline & \multicolumn{15}{|c|}{ Case number } \\
\hline & $\mathbf{1}$ & 2 & $\mathbf{3}$ & 4 & $\mathbf{5}$ & 6 & 7 & 8 & 9 & 10 & 11 & 12 & 13 & 14 & 15 \\
\hline Age at onset & 52 & 61 & 56 & 69 & 59 & 71 & 65 & 51 & 59 & 65 & 56 & 57 & 65 & 67 & 54 \\
\hline Sex & $F$ & $\mathbf{M}$ & M & $\mathbf{M}$ & $\mathbf{M}$ & $\mathbf{M}$ & $\mathrm{F}$ & $F$ & M & $\mathbf{M}$ & $\mathbf{F}$ & M & $\mathbf{F}$ & F & $\mathbf{M}$ \\
\hline Side first affected & $\mathrm{L}$ & $\mathbf{L}$ & $\mathrm{L}$ & $\mathbf{L}$ & $\mathbf{R}$ & $\mathrm{L}$ & $\mathbf{R}$ & $\mathrm{L}$ & $\mathrm{L}$ & $\mathbf{L}$ & $\mathbf{L}$ & $\mathrm{L}$ & $\mathbf{R}$ & $\mathrm{L}$ & $\mathrm{L}$ \\
\hline Duration of illness (yrs) & $10^{*}$ & $7^{*}$ & 5 & 8 & 4 & 4 & 3 & 9 & 8 & 4 & 5 & 6 & 7 & 4 & 3 \\
\hline \multicolumn{16}{|l|}{ Movement disorders } \\
\hline Akinesia, rigidity & + & + & + & + & + & + & + & + & + & + & + & + & + & + & + \\
\hline Focal reflex myoclonus & + & + & + & + & + & + & + & + & + & + & $(+)$ & - & + & + & $+?$ \\
\hline Postural-action tremor & $(+)$ & + & + & + & + & + & + & $(+)$ & + & - & + & + & $(+)$ & $(+)$ & - \\
\hline Limb dystonia & + & + & + & + & + & - & - & - & - & $(+)$ & + & $(+)$ & $(+)$ & + & - \\
\hline $\begin{array}{l}\text { Postural instability, } \\
\text { falls }\end{array}$ & + & + & - & - & + & + & - & + & + & + & + & + & + & - & + \\
\hline Athetosis & + & - & - & $(+)$ & - & - & - & + & - & - & - & - & - & + & - \\
\hline Orolingual dyskinesia & - & -- & - & + & - & - & - & - & - & - & - & - & + & - & - \\
\hline \multicolumn{16}{|l|}{ Cerebral cortical signs } \\
\hline Cortical sensory loss & + & + & $(+)$ & + & $(+)$ & + & $(+)$ & + & + & + & + & + & - & + & + \\
\hline Apraxia & + & $(+)$ & - & - & - & $(+)$ & + & - & $(+)$ & + & + & + & + & + & $(+)$ \\
\hline Alien limbs & + & + & + & - & + & + & + & - & - & + & + & + & - & - & + \\
\hline Frontal lobe reflexes & + & + & - & - & - & + & + & + & + & - & - & + & + & - & + \\
\hline Dementia & - & + & - & - & - & - & - & - & + & + & + & - & - & - & - \\
\hline Dysphasia & - & - & - & - & - & - & - & - & - & + & - & - & - & + & + \\
\hline \multicolumn{16}{|l|}{ Other manifestations } \\
\hline Hyperreflexia & + & + & + & + & - & + & + & + & + & + & + & - & + & - & + \\
\hline Babinski sign(s) & + & + & - & + & - & - & - & - & + & + & - & - & - & - & - \\
\hline Impaired ocular motion & + & + & - & - & + & - & - & - & - & + & + & + & + & - & + \\
\hline Impaired eyelid motion & + & + & - & - & + & + & - & - & + & + & - & + & + & - & - \\
\hline Dysarthria & + & + & - & - & - & - & - & + & - & + & - & - & + & + & + \\
\hline Dysphagia & - & + & - & - & - & - & - & - & - & - & 一 & - & + & - & - \\
\hline $\begin{aligned} \text { * } & \text { Patient died. } \\
\mathrm{R} & \text { Right. } \\
\text { L } & \text { Left. } \\
\text { ( ) Initial symptoms were re } & \text { Int } \\
\text { ? } & \text { Patient } 15 \text { had focal myc }\end{aligned}$ & $\begin{array}{l}\text { ted to } \\
\text { lonus, }\end{array}$ & $\begin{array}{l}\text { his man } \\
\text { ut it wa }\end{array}$ & $\begin{array}{l}\text { festatio } \\
\text { not pro }\end{array}$ & voked & y exte & stim & & & & & & & & & \\
\hline NB: Patients 1 and 8 also hac & drug-in & luced or & lingual & dyskin & sias. & & & & & & & & & & \\
\hline
\end{tabular}

the left hand and to a lesser degree in the left foot and right hand, and dystonic posturing of the left hand. Her tremor was now described as "jerky." She had a left Babinski sign and slightly impaired proprioception in the left foot.

In 1983, she began falling once or twice per week. Her speech deteriorated further and she was frequently unintelligible. The limb apraxias increased. When she was asked to perform a movement, there was either no motor response, or the specified limb, or another limb, made an incorrect gesture. This was usually followed by the patient stating, "I'm trying" or "I can't" (often her only decipherable verbal output). The left hand dystonia became more pronounced. Corticospinal tract signs increased with bilateral hyperreflexia and ankle clonus. Her "tremor" increased in irregularity and amplitude, becoming frankly myoclonic. Myoclonus in the right hand was easily elicited with touch, pinprick, finger tap, or action. She developed uncontrollable, repetitive right hand movements such as taking her glasses on and off, taking tissues in and out of her purse, and raising the hand to the face (ie, an alien limb). There were prominent bilateral grasp reflexes. A right frontal brain biopsy performed at this time revealed only subcortical gliosis.

Her disability continued to increase to the stage of complete incapacitation. She was admitted to a nursing home, where she became bedridden. She developed pneumonia and died in August 1986, at the age of 62, after a 10-year illness. Postmortem examination was performed.
Patient 2. A 61-year-old surgeon developed difficulty gloving, tying knots, and manipulating instruments with his left hand in 1981. He stated that he seemed to have "forgotten how" to use the hand in performing these tasks. Simultaneously he began to trip on stairs with his left foot. He was soon forced to retire from practice. In 1982 , a neurologist found an action tremor of the left hand, limb rigidity which was greater on the left, and prominent slowness and awkwardness of movements of the left hand. Levodopa was ineffective, and trihexyphenidyl caused blurred vision and hallucinations. Bromocriptine was discontinued because of gastrointestinal distress. $\mathrm{He}$ had a history of polymyalgia rheumatica and took prednisone for 2 years until 1982.

In 1983, he developed difficulty manipulating his right hand and abnormal posturing of his left arm. He required a handrail to walk down stairs. The following year he became unable to write because he could not "figure out how to do it," and he began falling frequently. He also became unable to read, both because he could not turn pages and because he had difficulty shifting his gaze from one line to the next. Examination in 1984 disclosed prominent apraxias of the upper limbs, especially the left, and moderate orolingual apraxia. There was mild difficulty with initiation of all ocular movements. There was a mild action tremor and dystonic posturing of the left arm, and bilateral bradykinesia and rigidity, greater on the left. At times the left hand would involuntarily rise and touch 
his lips. He was also noted to have repetitive involuntary movements of the right arm toward the face. Tendon and plantar reflexes were normal. Grasp reflexes were obtained easily, especially on the left. There was sensory inattention and impaired joint position sense in the left upper limb. His gait was intact, but he could not walk in tandem fashion because, as he stated, "I just don't know how to do it."

In 1985, his gait and right hand coordination deteriorated. During a bout of cystitis he was unable to walk because he could not "remember exactly what one had to do to walk." $\mathrm{He}$ complained of being unable to use a key and of putting the wrong leg into his trousers. He subsequently became virtually unable to use his upper limbs or to walk without assistance. Examination in 1986 demonstrated severe inability to perform saccades (which he did spontaneously) to command and gaze impersistence, impaired vertical optokinetic nystagmus, generalized hyperreflexia with flexor plantar responses, and impaired proprioception and graphesthesia bilaterally, in addition to the previous motor deficits. Six months later, he was confined to a wheelchair. His mental status examination was normal. There was intermittent apraxia of eye opening and closure. Optokinetic nystagmus was absent in all directions. He was unable to perform any simple orofacial or limb movements, except smiling, to command. His right arm was noted to elevate involuntarily at times.

He subsequently developed progressive dysarthria, hypophonia, and dysphagia. He lost all voluntary eye movements, although vestibulo-ocular reflexes remained intact, and he demonstrated left visual inattention. He became virtually unable to move his limbs. In 1987 his mental functions began to deteriorate, and he was intermittently disoriented. He displayed emotional incontinence. He developed myoclonic jerking of his left arm, which could be elicited by startle or touching the arm. Extensor plantar responses were obtained. He died in November 1987, at 68 years of age, 7 years after the onset of his symptoms.

Patient 5. A 59-year-old high school teacher developed numbness of his right thumb and index finger in 1985, first noted when he was unable to thread a bolt into a nut. Over the next 6 months the numbness spread to involve all right fingers. He stated he was able to detect temperature with that hand, but not to feel objects he touched. In 1986 he began having progressive difficulty with control of the right hand. He became unable to hold a pen properly, fasten buttons, or use a knife. He developed "spasms" of uncontrollable excessive gripping, resulting in crushed muffins or styrofoam cups. He also began noting a tremor of the hand when using it. A neurologist noted an action tremor and dystonic posturing of the right hand. Trials of propranolol and ethopropazine were without benefit.

Medical history included 2 nocturnal seizures in 1981. He was briefly treated with phenytoin, but after a head CT and an EEG were performed the medication was stopped without recurrence of the seizures. He also had a history of hypertension, treated with a diuretic, and remote left sciatica.

On examination in April 1987, he blinked less readily with the right eye than the left. There was intermittent dystonia of the right hand causing flexion of all fingers except the little finger, which was extended. There was a moderate postural and action tremor of the right arm and a mild action tremor of the left. There was mild rigidity and moderate akinesia of the right arm. Tendon reflexes were normal, apart from an absent left ankle jerk. Plantar responses were flexor. On sensory examination, the right fingertips were overly sensitive to light touch, pin, and temperature. Proprioception, graphesthesia, and 2-point discrimination were slightly diminished in the right hand. The gait showed a reduced right arm swing, but was otherwise normal. Handwriting was tremulous and obviously labored, and he had a tendency to grip the pen extremely tightly.

In June 1987, he suffered from transient flexion dystonia of the right little finger for 2 days. By March 1988, he was experiencing constant involuntary flexion of the right ring and little fingers, sufficient to cause pain from digging his nails into his palm. This was most prominent in the mornings and would resolve during the course of the day. On examination, myoclonus as well as the dystonia were evident in the right upper limb. The myoclonus could be provoked by action and percussion of the fingers as well as by light touch and pinprick. There were no other new clinical findings, and the other limbs remained normal. There was a mild left arm action tremor. Levodopa/carbidopa caused him to feel "worse" and clonazepam caused sedation and disequilibrium without improvement of his myoclonus.

By November 1989, myoclonus, dystonia, and rigidity had increased in the right hand and arm. The marked rigidity and dystonia resulted in severe pain in the right forearm, which eventually became his greatest complaint. Cortical sensation was more obviously disturbed in that hand. He had difficulty generating downward saccades, and vertical optokinetic nystagmus was markedly impaired. There was additional facial masking, bilateral akinesia and rigidity, and impaired vibration sensation in both feet. His gait was widely based and unsteady, and he could not perform tandem walking, apparently because of apraxia rather than ataxia. He complained of losing his balance and falling, but was unable to use a walker because of his right hand difficulties.

Patient 10. A 65-year-old retired machinist developed "stiffness" of the left hand, which he tended to hold "in a funny position," in 1985. He complained of pain in the left shoulder and was unable to abduct it beyond the horizontal; this resolved spontaneously after 2 years. His speech became slurred. He became unable to drive properly, often deviating to the left side of the road. His personality changed, becoming more aggressive. In 1987, a neurologist noted dysarthria, impaired repetition, right-left confusion, perseveration, prominent apraxias, left hand dystonia, hyperreflexia, and a left Babinski sign. The patient did not respond to serial trials of levodopa/ carbidopa, amantadine, trihexyphenidyl, benztropine, and baclofen.

Subsequently, his left arm began "shaking." He developed a choppy, short-stepped gait when approaching stairs or a chair. He fell several times, always backward. He began having difficulty manipulating his right hand and became unable to dress himself. He held a fork or spoon "in an odd way," and sometimes "missed" his lips with his coffee cup.

The history was provided by his wife. Although she insisted that he remained sharp mentally with an intact memory, he was unable to volunteer any complaints other than "I can't do the things I want to do." His wife noted that he was unable to figure out how to put an electric plug in a socket or how to push a vacuum cleaner. She had also observed that his lifelong facial tics which had been virtually continuous had disappeared over the past 8 months.

On examination in December 1988, he was alert and oriented, although the date was incorrect by 1 year. His speech was slow and slurred, with frequent stuttering. His verbal comprehension appeared intact. In responding to commands he demonstrated numerous orofacial and limb apraxias, frequent perseveration, and right-left confusion. Repetition was slightly impaired. There were occasional literal and verbal paraphasias. He remembered 1 of 3 objects at 3 minutes, 2 with prompting. He could not perform simple calculations. The cranial nerve examination was notable for severe reflex bleph- 
arospasm and impersistence of gaze and eye closure. Saccades were present in all directions but required multiple commands to elicit them. The range of eye movements was difficult to evaluate because of severe impersistence. Optokinetic nystagmus was present in all directions. There were numerous instances of forced eye clenching or wrinkling of his nose during the few minutes after his wife mentioned his tics, but they were rarely seen during the rest of the evaluation.

On motor examination, there was continuous dystonic posturing of the left hand. At times the left arm elevated in front of him, and he was unaware of this until his attention was called to it. There was action myoclonus of both upper limbs, greater on the left. Focal stimulus-sensitive myoclonus was present in the left hand. Rigidity was moderate in the legs, severe in the right arm, and extreme in the left arm. He was unable to perform rapid alternating movements because of apraxia. Tendon reflexes were pathologically brisk, especially in the legs. The plantar responses were flexor.

Joint position sense and graphesthesia were impaired bilaterally, more so on the left. He was unable to identify any objects by touch alone. He appreciated bilateral simultaneous touch randomly on either side. Sensation was otherwise normal. He walked with a wide base and could not stand with his feet together, but his stride was well preserved. The left arm did not swing while walking. Postural stability was normal.

Clinical observations. The cumulative manifestations of each patient's illness are given in table 1. The sequence in which they developed varied. Rarely were any 1 patient's deficits, as tabulated, all seen simultaneously. This is due to certain manifestations either displacing others (eg, myoclonus superseding tremor) or making their assessment difficult (eg, apraxia interfering with testing for limb akinesia). Thus, the findings on any single examination depended upon the time from onset of symptoms.

The mean age at onset ( 60 years), predominance of males, and tendency to involve the left side first were similar to previous reports. In patient 12 the leg was first involved; in all others the upper limb was the site of onset. The initial symptoms consisted of a roughly equal mixture of basal ganglia motor, cortical motor, and cortical sensory deficits. The sensory abnormalities and akinesia and rigidity were usually present at the time of the initial examination, though at times slight in degree. The postural and action tremor often evolved into discrete, irregular myoclonic jerks. Eventually, frank stimulus-sensitive and action myoclonus predominated.

Ideational and ideomotor apraxias could be disabling even early in the disorder (eg, patient 2). The apraxias interfered with movements of axial structures as well as the limbs. One striking example of the former was an apraxia of gaze in all directions in some patients, eg, in patient 1 where it was accompanied by apraxia of lid opening and closure. In 2 patients (nos. 2 and 13) the apraxia evolved into a supranuclear gaze paresis.

An important feature has been the asymmetry with which the disease presented and pursued its course. Frequently a single limb was involved for years before patients experienced more generalized deficits. With the cumulative motor diffculties of akinesia, rigidity, tremor, myoclonus, dystonia, and apraxia, the limb gradually lost all useful function. A characteristic feature of CBGD, when the clinical picture was fully established, was that of a stiff, dystonic, jerky, useless hand.

Five patients (nos. 1, 3, 5, 11, and 12) had hypertension. Four patients had a history of dysimmune diseases: hypothyroidism (no. 4), both hypothyroidism and bullous pemphigoid (no. 11), polymyalgia rheumatica (no. 2), and both ankylosing spondylitis and membranous glomerulonephritis (no. 6). With the exception of the hypothyroidism in patient 11 (4 years earlier) and the ankylosing spondylitis (remote), the immune dysfunction first became evident within a year before or after the onset of the neurologic illness. Two patients have had malignancies. Only 2 of the patients had a family history of neurologic disease; patient 8 had a sister with multiple sclerosis, and patient 14 has a sister with a malignant astrocytoma.

Only mild benefit has been obtained in a few patients with levodopa/carbidopa. Other antiparkinsonian drugs have not been effective. Myoclonus was dampened in 1 patient (no. 3) with clonazepam. Valproic acid, baclofen, dantrolene sodium, piracetam, and diazepam have also been ineffective in individual patients. Trials of botulinum A toxin injection (patients 5 and 13) into the rigid dystonic limbs have not been beneficial. In patient 13, painful dystonia and severe myoclonus failed to respond to stereotactic thalamotomy and right dorsal rhizotomy of C-5 to T-1. Resulting contractures and soft tissue infections eventually necessitated amputation of the right arm.

Investigations. General. Routine laboratory tests (ie, hematology, biochemistry, chest x-ray, ECG, etc) generally gave normal results, and there were no abnormalities that occurred in more than 1 patient. CSF was normal in 4 patients. In 1 patient (no. 4) the protein was mildly elevated and oligoclonal bands were detected; testing was not repeated.

Electrophysiology. EEG was normal in 4 (nos. 2, 4,5, and 6) of 8 patients. In 4 (nos. 1, 3, 9, and 11) there was diffuse bilateral slowing. One patient (no. 9) demonstrated additional focal slowing and occasional sharp transients over the right parasagittal area, contralateral to the side of greater clinical involvement. There were no EEG correlates of the myoclonic jerks in any of these patients; however, back-averaging techniques were not applied. Visual ( 3 patients), auditory (4 patients), and somatosensory ( 5 patients) evoked potential studies were not helpful, in general. However, in the somatosensory study of 1 patient (no. 3), stimulation of the median nerve on the clinically more affected (left) side produced a motor response in the muscles of the hand that occurred with a fixed latency in relation to the cortical evoked potentials. There was no such response on the right. The amplitudes of the somatosensory evoked responses have not been studied systematically.

Standard nerve conduction studies and EMG were normal in 5 patients and disclosed only a mild median neuropathy (carpal tunnel syndrome) in 2 others. In relaxed normal subjects, supramaximal median nerve stimulation results in a direct muscle (M) response and $F$ waves with a latency of about $25 \mathrm{msec}$, but no later potentials ${ }^{12}$; cutaneous stimulation also does not produce late responses. We studied long loop reflexes in 4 patients who had focal reflex myoclonus (nos. $3,4,5$, and 6). With surface electrodes over the abductor pollicis brevis (APB), and in some instances over forearm muscles, biceps, triceps, and deltoid, the response to supramaximal stimulation of the median nerve at the wrist and to stimulation of the index finger at $150 \%$ of the threshold for perception was obtained. The muscle action potentials were rectified and 20 sweeps were averaged. The peak amplitude of the averaged signals was then measured. Stimulation of the median nerve in affected limbs produced prominent late potentials with 
latencies between 44 and $55 \mathrm{msec}$ ( $\mathrm{C}$ waves) and amplitudes of $10 \%$ to $80 \%$ that of the $M$ wave (figure 1 ). Similar late potentials in APB were obtained by stimulation of the index finger with a latency longer by about $5 \mathrm{msec}$. In 2 subjects, late responses were also recorded from forearm muscles (latency, 38 to $45 \mathrm{msec}$ ) and deltoid (latency, $60 \mathrm{msec}$ ). These late responses were not present in the contralateral limbs and could not be obtained in 11 normal control subjects.

Imaging. In 8 patients (nos. 1, 2, 4, 7, 10,11, 12, and 13), CT showed asymmetric cerebral atrophy (figure 2 ), which was greater contralateral to the side first affected clinically. In 6 cases there was symmetric atrophy and in 1 (no. 5) CT was normal. Magnetic resonance imag-

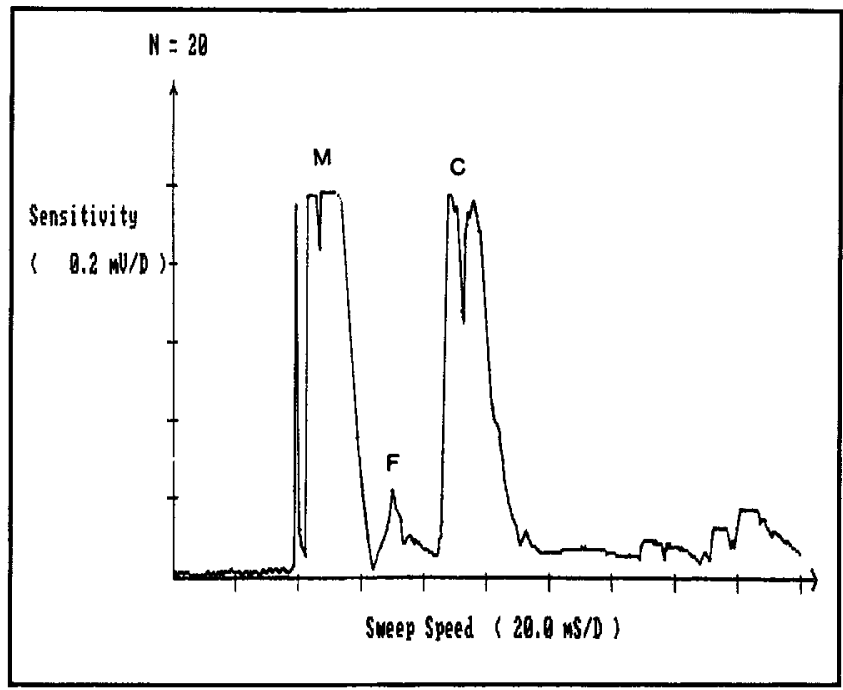

Figure 1. Median nerve stimulation in patient 3 produced normal $M$ waves and $F$ waves, plus large abnormal $C$ waves. Trace shown is the mean rectified response of 20 trials. $m V=$ millivolts, $m S=$ milliseconds, $D=$ division. ing (MRI) in 11 patients yielded no additional information, except the demonstration of ipsilateral midbrain and pontine hemiatrophy in patient 12 (figure 2C).

Pathology. Anatomy. Patient 1. At autopsy, the brain weighed 1,065 grams. Mild atrophy of the gyri of both cerebral hemispheres was noted.

Microscopic examination of selected areas of the left hemisphere (ipsilateral to the side of initial and greater clinical involvement) revealed pale, swollen neurons (figure 3) with eccentric nuclei that stained only faintly with cresyl violet in layers 5 and 6 of the cerebral cortex. These achromatic neurons were scattered throughout the cerebrum, but were most numerous in the medial frontal area (table 2). The cortical cytoarchitecture was preserved. Achromasia was also noted in some substantia nigra and caudate nucleus neurons. No Pick bodies were seen. Occasional senile plaques were noted, but only 1 neurofibrillary tangle was found, that in the locus ceruleus. The substantia nigra also showed severe neuronal loss and gliosis (figure 4), most prominent medially and posteriorly. Despite an extensive search, only 1 surviving neuron showed a faintly basophilic, rounded inclusion body (figure 5) as described by Gibb et al. ${ }^{6}$ No Lewy bodies were identified. The subthalamic nucleus demonstrated the presence of a remote infarction. The cerebellum and nucleus basalis of Meynert were normal.

Patient 2. At autopsy, the brain weighed 1,285 grams. The gross appearance of the cerebral hemispheres was normal, except for minimal symmetric ventricular dilation. Sections through the midbrain showed pallor and shrinkage of the substantia nigra. There was mild atherosclerosis of the blood vessels at the base of the brain. The brain otherwise appeared normal.

Microscopically, there was a moderate neuronal loss affecting layers 2 and 3 of the central frontoparietal cortex (table 2), associated with patchy spongiosis in

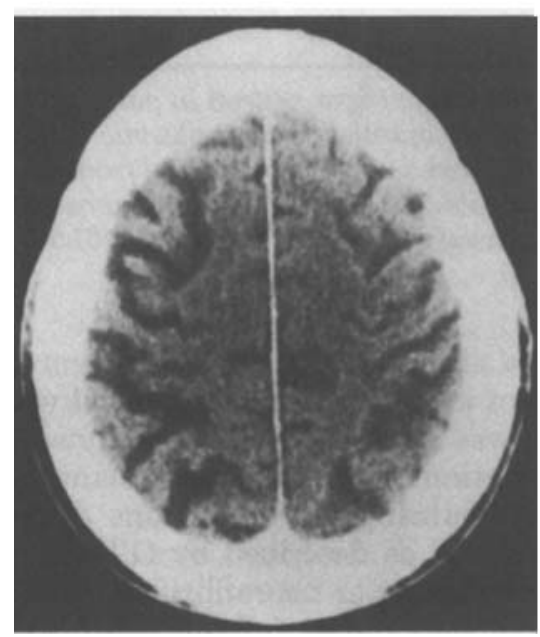

A

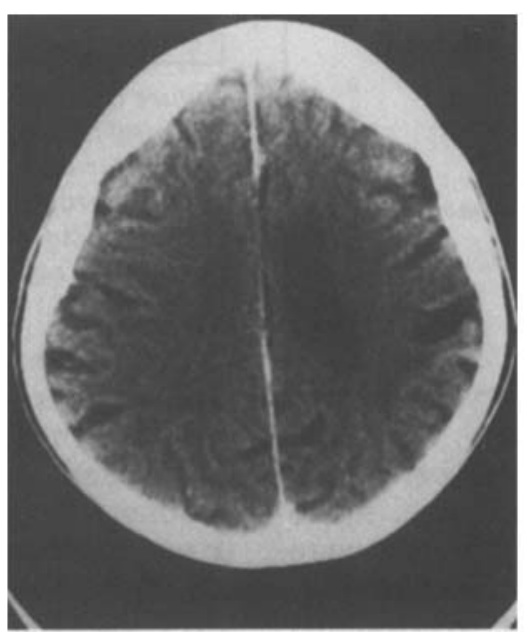

B

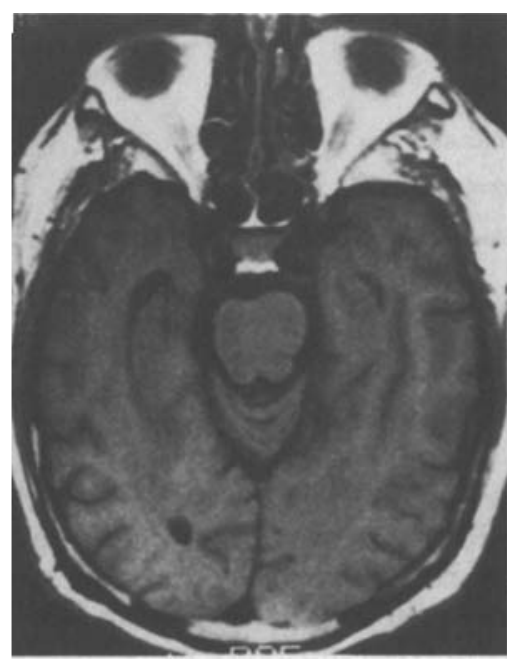

C

Figure 2. ( $A$ and B) CT demonstrating asymmetric cerebral atrophy in patients 2 ( $A$ ) and 7 (B). Lower views of the latter indicated the head was not tilted. (C) MRI demonstrating asymmetric atrophy of pons in patient 12. In each case the atrophy is worse on the side contralateral to the limb 1st and most severely affected. 


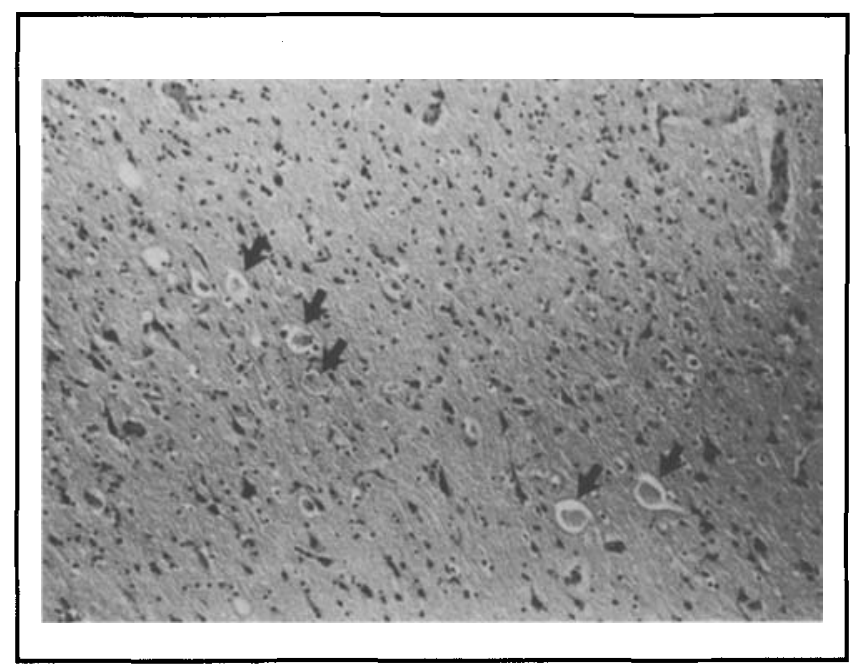

Figure 3. Achromatic neurons in cerebral cortex of patient 1 (arrows) (hematoxylin-phloxine-saffron; magnification $\times 117$ before $53 \%$ reduction).

Table 2. Distribution of microscopic findings at autopsy

\begin{tabular}{|c|c|c|c|c|}
\hline \multirow{2}{*}{$\begin{array}{l}\text { Microscopic } \\
\text { flndings }\end{array}$} & \multicolumn{2}{|c|}{ Case 1} & \multicolumn{2}{|c|}{ Case 2} \\
\hline & Achromasia & Gliosis & Achromasia & Gliogis \\
\hline \multicolumn{5}{|l|}{ Cerebral cortex } \\
\hline Frontal pole & - & - & 1 & 0 \\
\hline Medial frontal & 2 & 0 & 3 & 2 \\
\hline Precentral & 2 & 0 & 3 & 2 \\
\hline Postcentral & - & - & 3 & 2 \\
\hline Parietal & - & - & $1-3$ & $0-2$ \\
\hline Insula & 1 & 0 & - & - \\
\hline Temporal pole & 0 & 0 & 0 & 0 \\
\hline Temporal gyri & - & - & 1 & 0 \\
\hline Hippocampus & 1 & 0 & - & - \\
\hline Amygdala & - & - & 2 & 0 \\
\hline Striate & 1 & 0 & 0 & 0 \\
\hline Occipital & - & - & 0 & 0 \\
\hline \multicolumn{5}{|l|}{ Basel ganglia } \\
\hline Substantia nigra & 1 & 2 & 0 & 2 \\
\hline Caudate nucleus & 1 & 0 & 0 & 0 \\
\hline Other basal ganglia & - & - & 0 & 0 \\
\hline Brainstem & 0 & 0 & $1^{*}$ & 0 \\
\hline \multicolumn{5}{|l|}{ Cerebellum } \\
\hline Cortex & 0 & 0 & 0 & 0 \\
\hline Dentate nucleus & 0 & 0 & 0 & 0 \\
\hline Spinal cord & - & - & $1 \dagger$ & 0 \\
\hline \multicolumn{5}{|c|}{$\begin{aligned} \text { Achromasia: } 0 & =\text { no achromatic neurons, } 1=\text { few, } 2=\text { moderate numbers, and } \\
3 & =\text { abundant. } \\
\text { Gliosis; } 0 & =\text { none }, 1=\text { mild, } 2=\text { moderate, and } 3=\text { severe. }\end{aligned}$} \\
\hline \multicolumn{5}{|c|}{$\begin{array}{l}\text { * In cuneate nucleus. } \\
\dagger \text { In lumbosacral anterior horn. } \\
\text { - Not reported. }\end{array}$} \\
\hline
\end{tabular}

these laminae and mild astrocytosis in deeper layers. Swollen neurons, often with an eccentric nucleus (figure 6 ), were observed in layers 5 and 6 . These were eosinophilic on H-E staining and demonstrated absence of Nissl substance with cresyl violet. Argyrophilia was variably present, but no inclusions suggestive of Pick bodies were seen. There was moderate neuronal loss in layer 5 as well. All of the above findings were more pronounced in the right hemisphere. Other areas of the cortex showed little in the way of abnormalities.

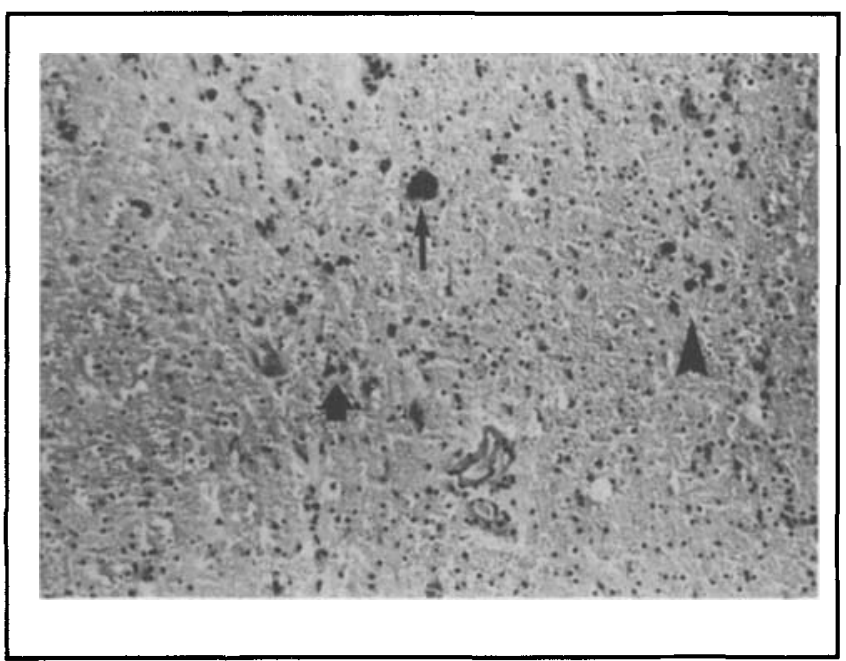

Figure 4. Neuronal loss and gliosis in substantia nigra of patient 1. There is only 1 residual neuron in this field (thin arrow). Melanin-containing macrophages are seen on the right (arrowhead). The small nuclei are mainly oligodendroglial, with some larger reactive astrocytes (wide arrow) (hematoxylin-phloxine-saffron; magnification $\times 146.2$ before $53 \%$ reduction).

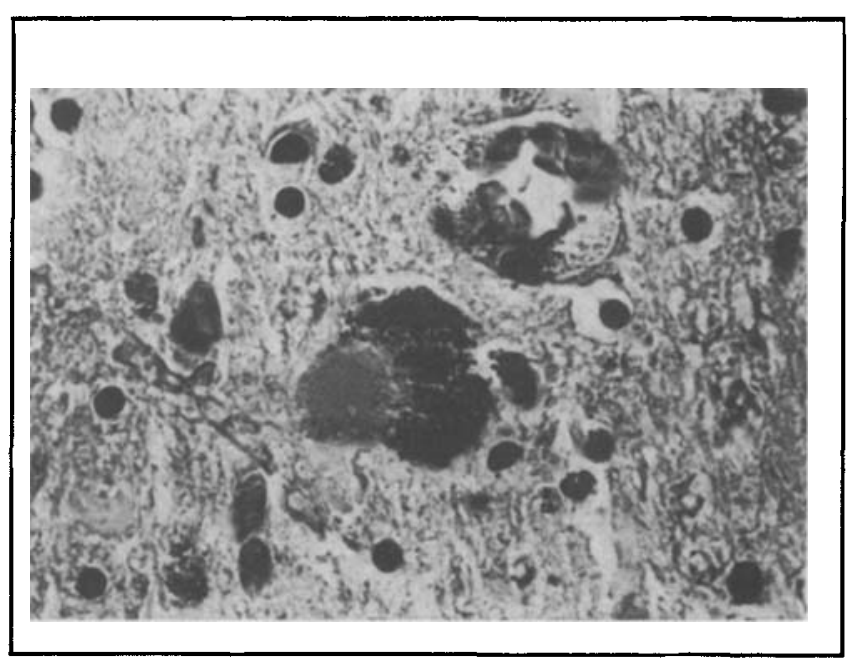

Figure 5. Residual substantia nigra neuron in patient 1 showing homogeneous, basophilic intracytoplasmic body. The latter is eccentric, appears well demarcated from the melanin granules, and abuts the cytoplasmic membrane (hematoxylin-phloxine-saffron; magnification $\times 1,161.6$ before $54 \%$ reduction).

In the substantia nigra, there was a severe neuronal loss, most prominent in the lateral $2 / 3$, somewhat worse on the right. This was associated with a fairly severe gliosis and accumulation of extracellular melanin. An estimated $8 \%$ of remaining nigral neurons demonstrated inclusion bodies as described by Gibb et al. ${ }^{6}$ There were no Lewy bodies or neurofibrillary tangles. Sections from the caudate nuclei, putamina, globi pallidi, subthalamic nuclei, hypothalami, mamillary bodies, and red nuclei were normal. The cerebellum was also normal. Several achromatic neurons were present in the amygdalae, cuneate nuclei, and the anterior horns of the lumbosacral region. Senile plaques were numer- 


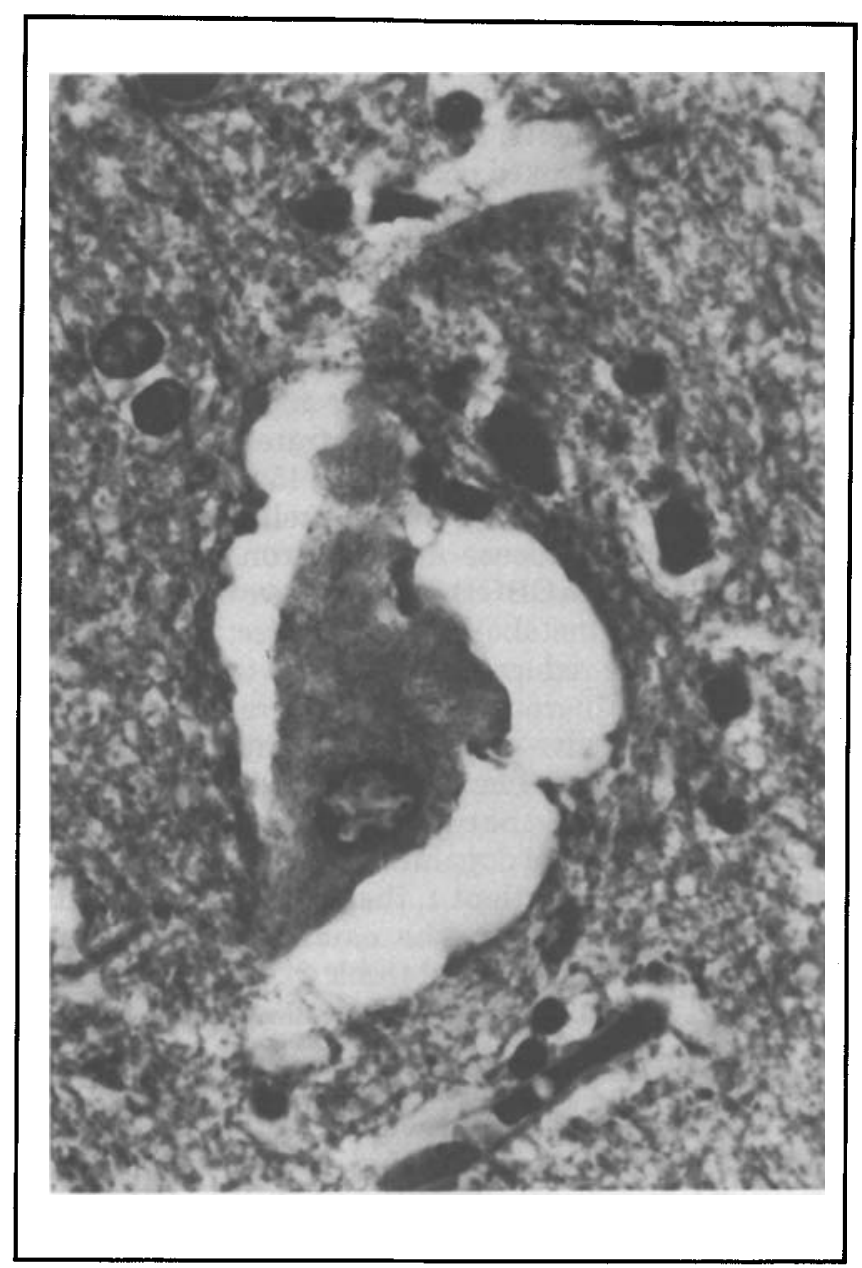

Figure 6. Achromatic neuron in cingulate cortex of patient 2. A swollen pyramidal neuron with granular cytoplasm is shown devoid of Nissl substance. The nucleus is slightly swollen and displaced peripherally. The perineuronal space is artifactual (Luxol fast blue, hematoxylin-eosin; magnification $\times 1,000)$.

ous in the cerebral cortex and infrequently seen in the hippocampi and amygdalae, but no neurofibrillary tangles were found.

Biochemistry. The right half of the brain of patient 1 was frozen (within 24 hours of death) at $-80^{\circ} \mathrm{C}$ for biochemical analysis. Concentrations of dopamine and homovanillic acid (HVA) were determined using the highperformance liquid chromatographic electrochemical procedure of Felice et al. ${ }^{13}$ Dopamine concentrations were profoundly reduced throughout the caudate nucleus and putamen (table 3 ), lower by $97 \%$ to $99 \%$ when compared with results from 5 age-matched control brains (mean age, 63 years). Dopamine was also depleted by $88 \%$ in the substantia nigra. The amount of HVA was diminished, though to a lesser extent than dopamine: $43 \%$ to $71 \%$ in the caudate nucleus, $54 \%$ to $83 \%$ in the putamen, and $69 \%$ in the substantia nigra (table 3 ).

Discussion. CBGD manifests an insidious onset and gradual progression of strikingly asymmetric features, consisting of symptoms and signs referable to dysfunction of both cerebral cortex and basal ganglia (table 4). Initial symptoms are most often due to tremor, apraxia,
Table 3. Brain dopamine and homovanillic acid in patient 1 and controls

\begin{tabular}{|lccccc|}
\hline & \multicolumn{2}{c}{ Dopamine } & \multicolumn{2}{c|}{ Homovanillic acid } \\
\cline { 2 - 5 } Brain region & Patient & Controls & Patient & Controls \\
Caudate & & & & \\
$\quad$ Rostral & 0.12 & $3.64 \pm 0.54$ & 2.46 & $4.29 \pm 0.93$ \\
$\quad$ Intermediate & 0.06 & $4.68 \pm 0.64$ & 2.42 & $5.26 \pm 1.01$ \\
$\quad$ Caudal & 0.03 & $4.21 \pm 0.60$ & 1.21 & $4.21 \pm 0.95$ \\
Putamen & & & & \\
$\quad$ Rostral & 0.18 & $5.60 \pm 0.26$ & 5.17 & $11.22 \pm 2.69$ \\
$\quad$ Intermediate & 0.01 & $5.54 \pm 0.37$ & 2.67 & $8.09 \pm 1.11$ \\
$\quad$ Caudal & 0.01 & $6.73 \pm 0.60$ & 1.17 & $6.91 \pm 1.61$ \\
Substantia nigra & 0.05 & $0.44 \pm 0.07$ & 1.31 & $4.29 \pm 0.92$ \\
Values are given as ng/mg tissue. Control values represent mean \pm \\
standard error of 5 controls. & & & \\
\hline
\end{tabular}

Table 4. Incidence of clinical manifestations in cortical-basal ganglionic degeneration

\begin{tabular}{|c|c|c|c|}
\hline & $\begin{array}{c}\text { Present } \\
\text { cases } \\
(n=15)\end{array}$ & $\begin{array}{c}\text { Previous } \\
\text { cases* } \\
(n=13)\end{array}$ & $\begin{array}{r}\text { Total (\%) } \\
(\mathbf{n}=\mathbf{2 8})\end{array}$ \\
\hline \multicolumn{4}{|l|}{ Movement disorders } \\
\hline Akinesia, rigidity & 15 & 13 & $28(100 \%)$ \\
\hline $\begin{array}{l}\text { Postural instability, } \\
\text { falls }\end{array}$ & 11 & 13 & $24(86 \%)$ \\
\hline Postural-action tremor & 13 & 9 & $22(79 \%)$ \\
\hline Limb dystonia & 10 & 6 & $16(57 \%)$ \\
\hline Focal reflex myoclonus & $14 \dagger$ & 1 & $15(54 \%)$ \\
\hline Orolingual dyskinesia & 2 & 3 & $5(18 \%)$ \\
\hline Athetosis & 4 & 1 & $5(18 \%)$ \\
\hline Limb chorea & 0 & 2 & $2(7 \%)$ \\
\hline Rest tremor & 0 & 1 & $1(4 \%)$ \\
\hline Axial dystonia & 0 & 1 & $1(4 \%)$ \\
\hline \multicolumn{4}{|l|}{ Cerebral cortical signs } \\
\hline Cortical sensory loss & 14 & 6 & $20(71 \%)$ \\
\hline Apraxia & 11 & 9 & $20(71 \%)$ \\
\hline Alien limbs & 10 & 4 & $14(50 \%)$ \\
\hline Frontal lobe reflexes & 9 & 4 & $13(46 \%)$ \\
\hline Dementia & 4 & 8 & $12(43 \%)$ \\
\hline Dysphasia & 3 & 3 & $6(21 \%)$ \\
\hline \multicolumn{4}{|l|}{ Other manifestations } \\
\hline Hyperreflexia & 12 & 6 & $18(64 \%)$ \\
\hline Babinski sign(s) & 5 & 8 & $13(46 \%)$ \\
\hline Impaired ocular motion & 8 & 5 & $13(46 \%)$ \\
\hline Impaired eyelid motion & 8 & 2 & $10(36 \%)$ \\
\hline Dysarthria & 6 & 4 & $10(36 \%)$ \\
\hline Dysphagia & 2 & 4 & $6(21 \%)$ \\
\hline Dysphonia & $0 \ddagger$ & 2 & $2(7 \%)$ \\
\hline Ataxia & 0 & $\S$ & $\S$ \\
\hline \multicolumn{4}{|c|}{$\begin{array}{l}\text { * Previous cases were reported in references } 3,4,5 \text {, and } 6 \text {. } \\
\text { † Including patient } 15 \text {, see table } 1 \text {. } \\
\$ \text { Our patient } 4 \text { developed dysphonia but was found to have laryngeal } \\
\text { cancer. } \\
\$ \text { The frequency of ataxia in other reports is impossible to determine, } \\
\text { since some authors appear to use this term to mean any type of } \\
\text { incoordination or gait disturbance. }\end{array}$} \\
\hline
\end{tabular}

limb dystonia, or cortical sensory disturbances (table 1). The fully developed syndrome presents a distinctive clinical picture. 
One of the most fascinating features in these patients is the appearance of the "alien limb" phenomenon. Brion and Jedynak ${ }^{14}$ coined this term in their report of 4 patients with callosal disconnection syndrome. They used the phrase "le signe de la main étrangère" (literally, "the sign of the foreign hand") to describe their subjects' lack of recognition of their own upper limbs as belonging to them. In this strict sense, the sign is indistinguishable from complete hemineglect as seen in parietal lobe disease. None of Brion and Jedynak's patients had involuntary movements. Bogen ${ }^{15}$ expanded the concept of the alien hand to mean a "circumstance in which one of the patient's hands ... behaves in a way which the patient finds 'foreign,' 'alien,' or at least uncooperative," thus redefining it as an active phenomenon. Brown ${ }^{16}$ delineated several features of this condition, including "a tendency for the arm to drift off and assume odd postures, especially when the eyes are closed or attention is diverted." This was the most common type of alien limb sign in our patients. Another extreme was present in patient 1 , whose hand frequently rose to her face, often touching the mouth or eyes. She was powerless to stop this movement; when directed to stop, she responded only "I can't." More often, complex movements such as pulling up a pantleg, touching another body part, or even grabbing hold of a bystander developed while the patients concentrated on tasks not involving the limb in question. At these times, patients would express consternation when the alien limb movements were brought to their attention. Recent authors have noted similar manifestations in patients with lesions of the supplementary motor area. ${ }^{17,18}$ However, Denny-Brown et al $^{19}$ described the phenomenon of "levitation," which bears a strong resemblance to some of the movements seen in our patients, in association with parietal lobe lesions. Thus, the exact anatomic site of involvement responsible for these movements is unclear, since both frontal and parietal lobes are markedly affected in CBGD. It is possible that these complex movements in CBGD patients have more than 1 site of origin, or may be "released" by lesions in more than 1 area.

Another important clinical feature of CBGD is the presence of ideational and ideomotor apraxias. Cognitive decline was notably mild or absent in many patients at a time when severe apraxias hampered most voluntary activity. The apraxia of gaze in patient 1 could have been mistaken for the gaze abnormality characteristic of progressive supranuclear palsy. However, there were distinct differences, most notably the equal involvement of horizontal and vertical eye movements, the marked discrepancy between gaze to command and spontaneous saccades at other times, and the preservation of optokinetic nystagmus at a time when saccades to command were absent. By contrast, 2 patients developed a more typical supranuclear gaze palsy late in the course of the illness, having evolved through a stage of ocular motor apraxia. Thus, it would seem that a spectrum of "supranuclear" eye movement disturbances exists in CBGD.

The focal reflex myoclonus present in our patients closely fits the description of cortical reflex myoclonus by Hallett et al. ${ }^{20}$ The large, unilateral $\mathrm{C}$ waves obtained in response to peripheral nerve stimulation (figure 1) in several of our patients, and the motor response timelocked to cortical evoked potentials in 1 patient, provide indirect evidence for a cortical origin of the myoclonus.

The original report of Rebeiz et $\mathrm{al}^{3}$ preceded the introduction of modern brain imaging techniques. However, 2 of their 3 patients demonstrated asymmetric atrophy on pneumoencephalography, worse on the side contralateral to the earlier and greater clinical involvement. CT and MRI demonstrated similar asymmetric atrophy (figure 2) in 8 of our 15 patients.

Initial reports ${ }^{10,11}$ and our own preliminary studies using fluorodeoxyglucose and positron emission tomography (PET) in CBGD patients have demonstrated thalamoparietal metabolic asymmetries; glucose metabolism is more reduced contralateral to the more affected side. ${ }^{18} \mathrm{~F}$-fluorodopa $\mathrm{PETs}^{11}$ (personal observations) provide in vivo evidence for striatal and cortical dopamine depletion. The marked reduction in lifelong tics of patient 10 could be considered further support for a reduction in cerebral dopamine. On postmortem analysis of the brain of patient 1 , the magnitude of striatal dopamine depletion in the caudate nucleus and putamen was relatively equal (table 3 ). This severe and generalized striatal dopamine depletion contrasts with PD, where a distinctly uneven pattern of striatal dopamine loss is found, the putamen being much more severely affected than the caudate nucleus. ${ }^{21}$ The biochemical findings corresponded to the more global nigral cell loss occurring in patient 1 than in $P D$ where the greatest changes are found in the middle and lateral thirds of the substantia nigra. ${ }^{22}$ Further cases are needed to determine the consistency of this finding, particularly since our patient 2 (in whom chemistry was not obtained) and other patients ${ }^{3,4,6}$ have shown a gradient of cell loss in the substantia nigra which was similar to that seen in PD, although the extent of cell loss in our patient 2 was greater than is typically present in PD. The less severe decrease in striatal levels of the dopamine metabolite HVA in patient 1 compared with the near total loss of dopamine is similar to biochemical observations in PD. ${ }^{23}$ To the extent that the HVA/ dopamine ratio provides an index of striatal dopamine activity, these data suggest a compensatory increase in the activity of surviving nigrostriatal neurons in CBGD.

There have been 7 published detailed autopsy reports on patients with CBGD.,3,6 The cerebral pathology in our 2 cases conforms very closely to that previously described, both in the finding of characteristic achromatic neurons (figures 3 and 6 ) and in the distribution of abnormalities in the medial and central cortex. Importantly, brain biopsy (patient 1) proved insensitive in making the diagnosis. All patients have also shown extensive substantia nigra changes. Involvement of other brain regions has been variable. Other areas of prominent cell loss and gliosis may include the lateral thalamic nuclei, subthalamic nucleus, locus ceruleus, globus pallidus, and red nucleus. Apart from the cerebral cortex, achromatic or swollen cells may be seen mainly in the subthalamic nucleus, red nucleus, 


\begin{tabular}{|c|c|c|c|c|c|}
\hline $\begin{array}{l}\text { Reference } \\
\text { no. }\end{array}$ & Diagnostic designation & Patients & $\begin{array}{l}\text { Age at } \\
\text { onset } \\
\text { (yrs) }\end{array}$ & $\begin{array}{l}\text { Clinical } \\
\text { features }\end{array}$ & $\begin{array}{l}\text { Distribution } \\
\text { of pathology }\end{array}$ \\
\hline 24 & $\begin{array}{l}\text { Extrapyramidal-pyramidal-parakinetic } \\
\text { syndrome in progressive encephalopathies with } \\
\text { achromatic neuronal swelling and cellular } \\
\text { gliosis in advanced age }\end{array}$ & $\begin{array}{c}2 \mathrm{~F} \\
1 \mathrm{M} \\
\text { (unrelated) }\end{array}$ & $\begin{array}{c}37,39 \\
56\end{array}$ & $\begin{array}{l}\text { Depression, } \\
\text { akinesia, falls, } \\
\text { Babinski signs, } \\
\text { dementia; death in } \\
1-2 \text { yrs }\end{array}$ & $\begin{array}{l}\text { All cerebral cortex, } \\
\text { thalamus, brainstem, } \\
\text { cerebellum }\end{array}$ \\
\hline 25 & Cortico-striato-pallido-nigral degeneration & $\begin{array}{l}4 \text { of } 6 \\
\text { siblings } \\
2 \mathrm{M}, 2 \mathrm{~F}\end{array}$ & $34-42$ & $\begin{array}{l}\text { Akinesia/rigidity } \\
\text { responsive to } \\
\text { levodopa; } \\
\text { death in } 3 \mathrm{yrs}\end{array}$ & $\begin{array}{l}\text { Cerebral cortex, } \\
\text { putamen, substantia } \\
\text { nigra (Lewy bodies), } \\
\text { hypothalamus, } \\
\text { brainstem }\end{array}$ \\
\hline 26 & $\begin{array}{l}\text { Cortico-striato-pallido-nigral degeneration } \\
\text { with neuronal achromasia }\end{array}$ & $\begin{array}{l}1 \mathrm{M} \\
\text { (unrelated to } \\
\text { above family) }\end{array}$ & 38 & $\begin{array}{l}\text { As in ref. } 25 \text {, } \\
\text { plus depression; } \\
\text { death in } 16 \text { yrs }\end{array}$ & As in ref. 25 \\
\hline 27 & Achromatic neuronal dystrophy & $\begin{array}{l}2 \text { siblings } \\
1 \mathrm{~F}, 1 \mathrm{M}\end{array}$ & 8 & $\begin{array}{l}\text { Progressive } \\
\text { myoclonic epilepsy; } \\
\text { death in } 10 \text { yrs }\end{array}$ & $\begin{array}{l}\text { Cerebellum, pons, } \\
\text { midbrain tegmentum, } \\
\text { cerebral cortex, } \\
\text { substantia nigra, } \\
\text { locus ceruleus, } \\
\text { thalamus }\end{array}$ \\
\hline 27 & Achromatic neuronal dystrophy & $1 \mathrm{M}$ & 49 & $\begin{array}{l}\text { Dementia, } \\
\text { pyramidal and } \\
\text { cerebellar signs } \\
2 \text { mos after head } \\
\text { trauma; death in } \\
3 \text { wks }\end{array}$ & Same as above \\
\hline
\end{tabular}

lateral thalamic nuclei, locus ceruleus, and occasionally other brainstem nuclei. Some previously reported cases have found degeneration with neuronal achromasia of cerebellar nuclei $i^{3}$ or a sensorimotor polyneuropathy. ${ }^{4}$ We did find the basophilic nigral inclusions described by Gibb et $\mathrm{al}^{6}$ as "unique" to CBGD, but the solitary inclusion body among hundreds of nigral neurons in patient 1 suggests it is not a sensitive marker. Whether it can be accepted as specific to CBGD will require further study of other neurologic controls and careful blinding of the pathologist to the proposed diagnoses.

Neuronal achromasia is not specific for CBGD. ${ }^{7} \mathrm{Sev}$ eral authors ${ }^{24-27}$ have reported patients who are clinically distinguishable but bear marked pathologic similarities to autopsied CBGD cases (table 5). Until more is known of the pathophysiology of these disorders, we would recommend that the confirmation of the diagnosis of CBGD by pathologic studies requires that it follows in the wake of an appropriate clinical course.

The achromatic neurons of CBGD brains bear a resemblance to those found in Pick's disease. , $^{4,6}$ "Swollen, chromatolytic neurons" found in patients with pure dementing illnesses interpreted as atypical Pick's disease also have been likened to the achromatic neurons of CBGD. ${ }^{28}$ There appears to be a consensus that the latter never show Pick bodies or any significant degree of argyrophilia. One of the patients with atypical Pick's disease cited above also showed chromatolysis in pigmented substantia nigra neurons, suggesting a further link between Pick's and CBGD. ${ }^{28}$
Our observations have not provided definitive insights into possible causes of CBGD. There was a surprisingly high incidence of dysimmune phenomena in our patients. Whether this or other systemic disorders are important to the pathogenesis of CBGD will require further study of larger numbers of patients.

CBGD represents a distinctive clinical-pathologic entity. The experience presented here emphasizes that the diagnosis can be made during life (as was the case in both of our autopsied patients) based on the typical history and findings on examination. Continued study of this disorder may expand our knowledge of the spectrum of clinical manifestations and improve our diagnostic ability.

\section{Acknowledgments}

We wish to thank the following physicians for helping to make their patients available to us: D. Waller, MD; W. McIlroy, MD; S. Jiaravuthisan, MD; A. Birnbaum, MD; R. Rutherford, MD; D. Crisp, MD; J. Norris, MD; D. Hobson, MD; R. Daroff, MD; T. Tucker, MD; J. Bonner, MD; D. Ewing-Wilson, DO; P. Sweeney, MD; B. Reznick, MD; M. Shandling, MD; M. Devereaux, MD; and J. Trott, MD. We also thank $\mathrm{S}$. Kish, $\mathrm{PhD}$, for the biochemical brain analysis, Y. Furukawa, MD, for translation of the Japanese references, and S. Garnett, MB, for the PET information.

\section{References}

1. Steele JC, Richardson JC, Olszewski J. Progressive supranuclear palsy. Arch Neurol 1964;10:333-358. 
2. Shy GM, Drager GA. A neurological syndrome associated with orthostatic hypotension. Arch Neurol 1960;2:511-527.

3. Rebeiz JJ, Kolodny EH, Richardson EP. Corticodentatonigral degeneration with neuronal achromasia. Arch Neurol 1968;18:20-33.

4. Case records of the Massachusetts General Hospital. N Engl J Med 1985;313:739-748.

5. Watts RL, Williams RS, Growdon JD, Young RR, Haley EC Jr, Beal MF. Corticobasal ganglionic degeneration. Abstract. Neurology 1985;35(suppl 1):178.

6. Gibb WR, Luthert PJ, Marsden CD. Corticobasal degeneration. Brain 1989;112:1171-1192.

7. Dickson DW, Yen SH, Suzuki KI, Davies P, Garcia JH, Hirano A Ballooned neurons in select neurodegenerative diseases contain phosphorylated neurofilament epitopes. Acta Neuropathol (Berl) 1986;71:216-223.

8. Watts RL, Mirra SS, Young RR, Burger PC, Villier JA, Heyman A. Cortico-basal ganglionic degeneration (CBGD) with neuronal achromasia: clinical-pathological study of two cases. Abstract. Neurology 1989;39(suppl 1):140.

9. LeWitt P, Friedman J, Nutt J, Korczyn A, Brogna C, Truong D. Progressive rigidity with apraxia: the variety of clinical and pathological features. Abstract. Neurology 1989;39(suppl 1):140.

10. Eidelberg D, Moeller JR, Sidtis JJ, et al. Corticodentatonigral degeneration: metabolic asymmetries studied with ${ }^{18 F}$-fluorodeoxyglucose and positron emission tomography. Abstract. Neurology 1989;39(suppl 1):164.

11. Sawle GV, Brooks DJ, Thompson PD, Marsden CD, Frackowiak RSJ. PET studies on the dopaminergic system and regional cortical metabolism in corticobasal degeneration. Abstract. Neurology 1989;39(suppl 1):163.

12. Kelly JJ, Sharbrough FW, Daube JR. A clinical and electrophysiological evaluation of myoclonus. Neurology 1981;31:581-589.

13. Felice LJ, Felice JD, Kissinger PT. Determination of catecholamines in rat brain parts by reverse-phase ion-pair liquid chromatography. J Neurochem 1978;31:1461-1465.

14. Brion S, Jedynak CP. Troubles du transfert interhémisphérique (callosal disconnection). Rev Neurol (Paris) 1972;126:257-266.

15. Bogen JE. The callosal syndrome. In: Heilman KM, Valenstein E, eds. Clinical neuropsychology. New York: Oxford University Press, 1979:308-359.
16. Brown JW. Frontal lobe syndromes. In: Frederiks JAM, ed. Clinical neuropsychology. Handbook of clinical neurology, vol. 45. Amsterdam: Elsevier, 1985:23-41.

17. Goldberg G, Mayer NH, Toglia JU. Medial frontal cortex infarction and the alien hand sign. Arch Neurol 1981;38:683-686.

18. McNabb AW, Carroll WM, Mastaglia FL. "Alien hand" and loss of bimanual coordination after dominant anterior cerebral artery territory infarction. J Neurol Neurosurg Psychiatry 1988;51:218-222.

19. Denny-Brown D, Meyer JS, Horenstein S. The significance of perceptual rivalry resulting from parietal lobe lesions. Brain 1952;75:433-471.

20. Hallett M, Chadwick D, Marsden CD. Cortical reflex myoclonus. Neurology 1979;29:1107-1125.

21. Kish SJ, Shannak K, Hornykiewicz O. Uneven pattern of dopamine loss in the striatum of patients with idiopathic Parkinson's disease. N Engl J Med 1988;318:876-880.

22. Hassler R. Zur Pathologie der Paralysis agitans und des postenzephalitischen Parkinsonismus. J Psychol Neurol Lpz 1938;48:387-476.

23. Bernheimer H, Birkmayer W, Hornykiewicz O, Jellinger K, Seitelberger F. Brain dopamine and the syndromes of Parkinson and Huntington: clinical, morphological and neurochemical correlations. J Neurol Sci 1973;20:415-455.

24. Jacob H. Extrapyramidal-pyramidal-parakinetic syndrome in progressive encephalopathies with achromatic neuronal swelling and cellular gliosis in advanced age. Acta Neuropathol (Berl) 1971;17:341-352.

25. Maeda S, Yokoi S, Isaka K, Numabe T. An unusual type of familial extrapyramidal disease: cortico-striato-pallido-nigral degeneration. Seishin Shinkeigaku Zasshi 1973;75:657-672.

26. Maeda S, Takahashi S, Isaka K, Aihara Y, Fujita T. An autopsy case of cortico-striato-pallido-nigral degeneration with neuronal achromasia. Rinsho Shinkeigaku 1977;17:61-66.

27. Seitelberger F. Achromatic neuronal dystrophy. In: Kornyey S, Tariska S, Gosztonyi G, eds. VIIth International Congress of Neuropathology Proceedings, vol 1. Amsterdam: Excerpta Medica, 1975:299-305.

28. Clark AW, Manz HJ, White CL, Lehmann J, Miller D, Coyle JT. Cortical degeneration with swollen chromatolytic neurons: its relationship to Pick's disease. J Neuropathol Exp Neurol $1986 ; 45: 268-284$. 


\section{Neurology}

\section{Cortical-basal ganglionic degeneration}

D. E. Riley, A. E. Lang, A. Lewis, et al.

Neurology 1990;40;1203

DOI 10.1212/WNL.40.8.1203

\section{This information is current as of August 1, 1990}

\section{Updated Information \& Services}

\section{Citations}

Permissions \& Licensing

Reprints including high resolution figures, can be found at: http://n.neurology.org/content/40/8/1203.full

This article has been cited by 26 HighWire-hosted articles: http://n.neurology.org/content/40/8/1203.full\#\#otherarticles

Information about reproducing this article in parts (figures,tables) or in its entirety can be found online at:

http://www.neurology.org/about/about_the_journal\#permissions

Information about ordering reprints can be found online:

http://n.neurology.org/subscribers/advertise

Neurology $®$ is the official journal of the American Academy of Neurology. Published continuously since 1951, it is now a weekly with 48 issues per year. Copyright (C) 1990 by Edgell Communications, Inc.. All rights reserved. Print ISSN: 0028-3878. Online ISSN: 1526-632X.

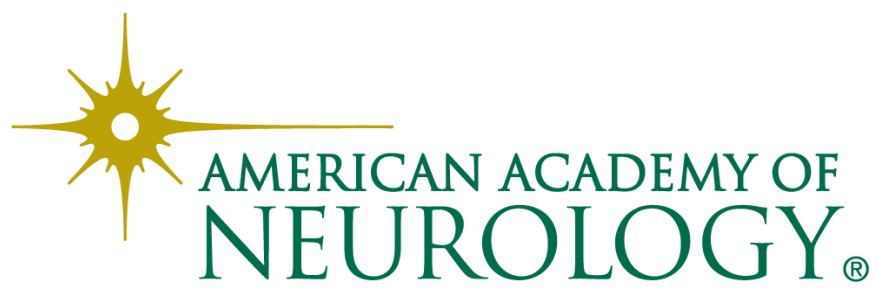

